\title{
Epidemiology and Clinical Presentation of Pandemic Influenza A (H1N1) among Hospitalized Children in Kuwait
}

\author{
Abdullah F. Owayed ${ }^{a, b}$ Entesar H. Husain ${ }^{a, b}$ Ahmad Al-Khabaz ${ }^{b}$ \\ Hanan Y. Al-Qattan ${ }^{c}$ Nufoud Al-Shammari ${ }^{b}$ \\ Departments of Pediatrics, ${ }^{a}$ Faculty of Medicine, ${ }^{b}$ Mubarak Al-Kabeer Hospital and 'Farwaniya Hospital, \\ Kuwait City, Kuwait
}

\section{Key Words}

Influenza A H1N1 · Kuwait · Children

\begin{abstract}
Objective: To describe the epidemiological and clinical characteristics of children hospitalized for the 2009 influenza A H1N1 infection in Kuwait. Materials and Methods: A retrospective chart review of hospitalized children with laboratory-confirmed influenza A H1N1 infection in two hospitals in Kuwait was conducted. Epidemiological characteristics, clinical features, risk factors for severe disease, complications and mortality were analyzed. Results: The medical records of 197 children hospitalized for the 2009 pandemic H1N1 infection from August 2009 to January 2010 were reviewed. The majority of the children $(104 ; 52.8 \%)$ were admitted during the month of October. The median age was 2 years. Most of the admitted children were in two age categories: 64 infants $\leq 1$ year (32\%) and 62 schoolchildren $>5$ years (31\%). The most frequent presentations were fever in 193 (98\%), cough in 155 (79\%) and runny nose in 105 (53\%) cases. The majority of the admitted children $(109 ; 55 \%)$ had been previously healthy. All children received an antiviral agent (oseltamivir), and antibiotics were administered to 147 (75\%). Bacterial co-infections occurred in 3 (1.5\%) of all hospitalized chil-
\end{abstract}

dren. Six (3\%) children were admitted to the intensive care unit, of whom $4(66 \%)$ required artificial ventilation. There was only 1 mortality. Conclusions: The pandemic H1N1 infection was associated with a wide spectrum of clinical manifestations. The majority of hospitalized children had previously been healthy. Most of the admitted children had an uncomplicated clinical course.

Copyright ๑ 2011 S. Karger AG, Basel

\section{Introduction}

Swine influenza was first isolated in 1930 [1] and has caused periodic outbreaks among humans [2-5]. In March 2009, a new strain of pandemic influenza A (H1N1) virus emerged in Mexico, where it caused a large outbreak [6] with subsequent worldwide spread. In early June 2009, the World Health Organization raised the pandemic alert level to phase 6 , which reflected the fact that the virus caused sustained community level outbreaks in at least 1 other country in another WHO region [7]. In July 2009, Kuwait confirmed influenza A infection in 4 Kuwaiti citizens who returned from the USA. All initial cases were admitted to the Infectious Diseases Hospital for the purpose of isolation. With the continued rise

\section{KARGER \\ Fax +41613061234 \\ E-Mail karger@karger.ch}

www.karger.com (c) 2011 S. Karger AG, Basel

1011-7571/12/0213-0254\$38.00/0

Accessible online at:

www.karger.com/mpp
Dr. Entesar H. Husain

Department of Pediatrics, Faculty of Medicine

PO Box 24923

13110 Safat (Kuwait)

E-Mail ehusain@ hsc.edu.kw 


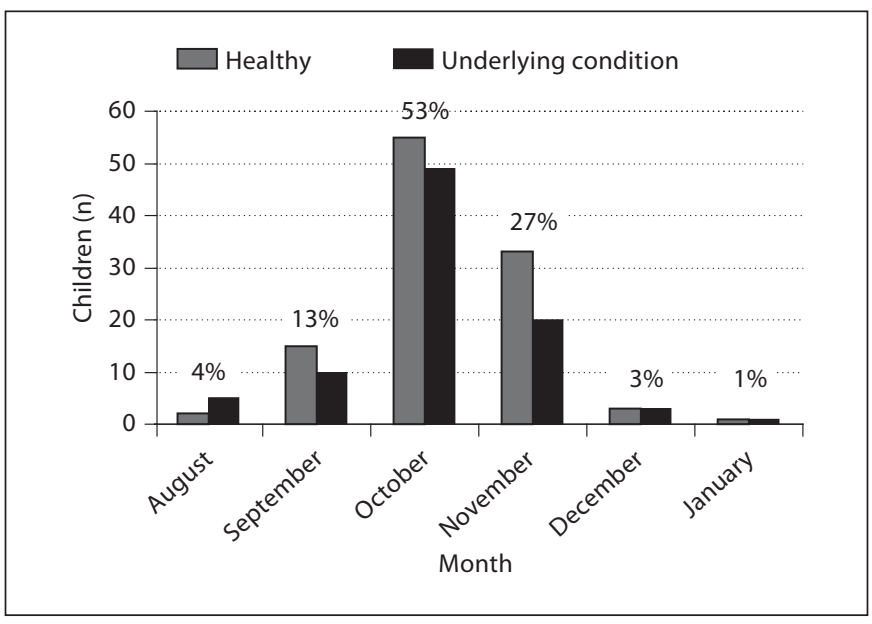

Fig. 1. Number of hospitalized children with influenza A H1N1 during the months of the study.

in the number of the cases, the Ministry of Health approved in August the admission of the cases of influenza A (H1N1) into isolation wards of the general hospitals.

In this study, we examined the demographic and clinical features as well as laboratory findings and outcome of children with confirmed H1N1 influenza virus infection admitted to two tertiary hospitals during the period of the pandemic in Kuwait.

\section{Materials and Methods}

The two tertiary hospitals were Mubarak Al-Kabeer and Farwaniya. These two hospitals were selected because they represent the busiest pediatric service in Kuwait.

The study was conducted after obtaining approval from the Ministry of Health and the hospital's Board of Ethics. A retrospective review of medical records of children hospitalized with influenza A (H1N1) was conducted from August 2009 to January 2010. Children were hospitalized with influenza-like illness which included the following: axillary temperature of $\geq 38^{\circ} \mathrm{C}$ and cough and/or sore throat. Temperature of $\geq 38^{\circ} \mathrm{C}$ was selected because it is the temperature included in the WHO's definition of influenza-like illness and accepted by the Ministry of Health, Kuwait. Influenza A ( $\mathrm{H} 1 \mathrm{~N} 1)$ virus was confirmed by a real-time reverse-transcriptase polymerase chain reaction assay, from a nasopharyngeal swab combined with a throat swab.

The following data were collected from the medical records: age, gender, presenting symptoms as observed by the parent and signs as documented by the treating pediatrician, preexisting chronic conditions associated with a high risk for influenza-related complications, radiological and laboratory findings, therapeutic measures and outcome.

Epidemiology and Clinical Presentation of H1N1 in Children in Kuwait
Table 1. Distribution of health conditions among 88 children with underlying comorbid conditions admitted with 2009 influenza A $\mathrm{H} 1 \mathrm{~N} 1$

\begin{tabular}{lrl}
\hline Category & $\mathrm{n}$ & $\%$ \\
\hline Bronchial asthma & 56 & 64 \\
Neurological disease & 13 & 15 \\
$\quad$ Seizures/epilepsy & 5 & \\
$\quad$ Cerebral palsy & 6 & \\
$\quad$ Muscle disease & 2 & 9 \\
Congenital heart disease & 8 & 4.5 \\
Hematological & 4 & \\
$\quad$ Sickle cell anemia & 3 & 3 \\
$\quad$ Hemophilia & 1 & \\
Endocrine & 3 & \\
$\quad$ Diabetes (type 1) & 2 & 2 \\
$\quad$ Hypothyroidism & 1 & 2 \\
Trisomy 21 & 2 & \\
Nephrotic syndrome & 2 & \\
\hline
\end{tabular}

Statistical analysis was performed using SPSS 16.0 for Windows (SPSS Inc., Chicago, Ill., USA). Basic statistical parameters calculated and included were frequency, proportions, mean and median. For comparison between clinical presentations among various age groups, significant differences among categorical variables were identified using the $\chi^{2}$ test. A p value of $<0.05$ was considered to be significant.

\section{Results}

A total of 255 children were admitted to the two hospitals with confirmed 2009 influenza A H1N1 during the period from August 11, 2009, to January 26, 2010. Only information on 193 children was available for analysis and is presented here.

The median age was 2 years (range: 7 days to 12 years). The age categories of admitted children were as follows: infants ( $\leq 1$ year), 64 (32\%); toddlers (2-3 years), 56 (29\%); preschool children (4-5 years), 15 (8\%), and school children (>5 years), 62 (31\%). Males comprised 117 (59\%) of admitted children. The majority $(104 ; 52.8 \%)$ of the children included in the study were admitted during the month of October. The distribution of admission during the months of the study is shown in figure 1. The mean duration of hospitalization \pm SD was $4.5 \pm 3.6$ days. Of the admitted children, 109 (55\%) were healthy. The remaining had underlying medical conditions as shown in table 1.

The mean temperature on admission \pm SD was 38.2 $\pm 0.8^{\circ} \mathrm{C}$ with the mean duration $\pm \mathrm{SD}$ of $4 \pm 2$ days 
Fig. 2. Distribution of radiological findings with underlying health conditions.

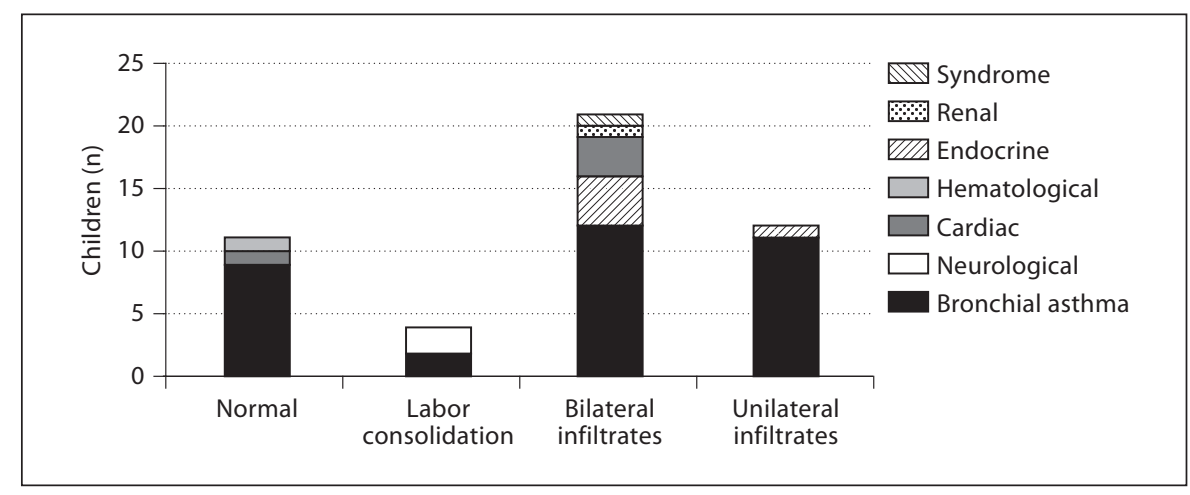

prior to admission. There were $43(22.5 \%)$ children with temperatures of $\geq 39^{\circ} \mathrm{C}$ on admission. The most common presentations on admission were: fever in 193 (98.25\%), cough in 155 (76\%) and runny nose in 105 (53.5\%) cases. Other clinical presentations are summarized in table 2. Vomiting and sore throat were significantly reported among school-age children (30, 50\%, 40, $66 \%, \mathrm{p}<0.05)$, respectively.

The hematological findings were: the mean white blood cell count \pm SD was $9 \pm 5.7 \times 10^{9} / 1$ (normal range: $\left.4.3-10.8 \times 10^{9} / 1\right)$; leukocytosis was seen in 54 patients $(28.4 \%)$ while leucopenia was seen in $20(10.5 \%)$. Leukocytosis was seen in $31(48 \%)$ of the infants $(\mathrm{p}<0.05)$ when compared to older children. The mean absolute neutrophil count $\pm \mathrm{SD}$ was $4.8 \pm 4.5 \times 10^{9} / 1$ (normal range: $\left.1.5-7.0 \times 10^{9} / 1\right)$. Neutrophilia was seen in 33 (17.6\%), while neutropenia was observed in $40(21 \%)$. The mean absolute lymphocyte count $\pm \mathrm{SD}$ was $2.9 \pm 2.3 \times$ $10^{9} / 1$ (normal range: $1.0-3.5 \times 10^{9} / \mathrm{l}$ ). Lymphocytosis was seen in $56(28.4 \%)$ with lymphopenia in 35 (17.8\%). Among children with lymphopenia, 24 (68\%) were in the school-age category $(\mathrm{p}<0.05)$. The mean platelet count was $286.7 \pm 108 \times 10^{9}$ (normal range: $150-350 \times 10^{9}$ ). Thrombocytosis was seen in 18 (9.7\%), thrombocytopenia in 12 (6.5\%).

Of the 91 (46\%) children in whom chest radiographs were performed, 30 (33\%) showed normal radiographs. The most common radiological finding was bilateral infiltrates in 30 (33\%). Other findings included: unilateral infiltrates in 22 (24\%), lobar consolidation in 7 (8\%) and pleural effusion in 2 (2\%). The distribution of the radiological findings in relation to the underlying health conditions is given in figure 2. Blood cultures performed on all febrile children (193) showed that 3 (1.5\%) were positive for the following organisms: Streptococcus pneumoniae, Klebsiella pneumoniae, Salmonella group G1.
Table 2. Clinical presentations in children with influenza A H1N1 $(\mathrm{n}=197)$

\begin{tabular}{lrc}
\hline Clinical feature & $\mathrm{n}$ & $\%$ \\
\hline Fever & 193 & 98 \\
Respiratory distress & 47 & 24 \\
Cough & 155 & 79 \\
Runny nose & 105 & 53 \\
Tachypnea & 41 & 21 \\
Wheezes & 25 & 13 \\
Sore throat & 12 & 6 \\
Vomiting & 72 & 37 \\
Diarrhea & 29 & 15 \\
Abdominal pain & 5 & 2.5 \\
Febrile convulsions & 16 & 8 \\
Conjunctivitis & 2 & 1 \\
Headache & 3 & 1.5 \\
Myalgia & 3 & 1.5 \\
\hline
\end{tabular}

The patient who had a positive blood culture for S. pneumoniae was admitted to the intensive care unit (ICU) for hemodynamic monitoring and did not require assisted ventilation.

Of the 6 children (3\%) admitted to the ICU, 4 (66\%) required artificial ventilation. Five out of these 6 children had the following underlying health conditions: bronchial asthma (1), bronchial asthma and seizure disorder (3), congenital heart disease (1) and congenital heart disease and seizure disorder (1). Complications were reported in 3 children; the first had previously been healthy but had encephalitis, the second was a child with cerebral palsy who developed marked elevation of liver transaminases, and the third with an underlying seizure disorder had myositis. In the series, only 1 death occurred in a 3-monthold female with spinal muscular atrophy type 1 . 
Of the 197 cases, 147 (75\%) were administered antibiotics while an antiviral agent (oseltamivir) was administered to all of the children except 1 because of parental refusal. There were $76(38.5 \%)$ who needed a $\beta_{2}$ agonist nebulizer, $38(50 \%)$ had bronchial asthma $(\mathrm{p}=0.00)$. A nebulized steroid was administered to 57 (29\%) of whom $34(60 \%)$ had bronchial asthma $(\mathrm{p}=0.00)$. Systemic steroids were administered to $35(17.8 \%)$ patients of whom $20(57 \%)$ had bronchial asthma $(\mathrm{p}=0.00)$.

\section{Discussion}

This study summarized the clinical characteristics of influenza A (H1N1) infection among hospitalized children in Kuwait similar to those of seasonal influenza [6, $8-11]$. The most commonly reported symptoms were fever, cough and runny nose. Older children had presented with significant gastrointestinal symptoms of vomiting and diarrhea which was consistent with other reports $[6$, $10,11]$.

The neurological complications related to influenza A (H1N1) infection are poorly defined. Reported complications include mental status changes, behavior alteration, seizure disorder and focal neurological deficit $[8,9,12]$. Sixteen (8.2\%) of our patients presented with febrile convulsions, and 1 patient developed encephalopathy and recovered completely. A case of influenza A H1N1 encephalitis was recently reported from Kuwait [13].

The high rate (45\%) of hospitalization among children with underlying chronic medical conditions is similar to that reported in children with chronic medical conditions hospitalized with seasonal influenza of $37-43 \%$ [14, 15]. Bronchial asthma was the most commonly associated underlying risk factor accounting for $64 \%$ of all admissions with underlying health conditions as previously reported [9].
Despite the high proportion of children with an underlying chronic medical condition, only $3 \%$ of children were admitted to the ICU, which is quite below a higher rate of $20-26 \%$ reported in other studies $[16,17]$. This low percentage might reflect the milder form of the infection among children in Kuwait and that half of the admitted children had previously been healthy.

An additional risk factor that was noticeable during the H1N1 influenza pandemic was the reduction in the white cell count, especially the lymphocyte count. Among the 6 patients admitted to the ICU, 3 had lymphopenia similar to studies from India, California and Mexico [1822]. In Mexico, the analysis of 18 deaths caused by H1N1 infection in previously healthy subjects revealed lymphopenia in $16 \%$ of them; apparently lymphopenia is an important risk factor and patients should be closely observed, especially those with underlying medical conditions.

The low rate of bacterial co-infection in our study $(1.5 \%)$ is similar to that of other reports showing a lack of bacterial co-infections in hospitalized patients with H1N1 [21, 23, 24]. The empiric antibiotics administration to the majority of our patients (75\%) was due to the inability of currently existing laboratory and radiographic modalities to accurately differentiate bacterial from viral etiologies.

\section{Conclusion}

Children with H1N1 influenza virus infection had a wide spectrum of clinical manifestations. Our study confirms that the highest rate of complications was observed in children with bronchial asthma, underlying neurological conditions and lymphopenia. Treatment with antiviral oseltamivir appeared to have no major adverse effects.

\section{References}

1 Shope, RE: Swine influenza: filtration experiments and etiology. J Exp Med 1931;54:373385.

- 2 Shinde V, Bridges CB, Uyeki TM, Shu B, Balish A, Xu X, Lindstrom S, Gubareva LV, Deyde V, Garten RJ, et al: Triple-reassortant swine influenza A (H1) in humans in the United States, 2005-2009. N Engl J Med 2009;360:2616-2625.

- 3 Wells DL, Hopfensperger DJ, Arden NH, Harmon MW, Davis JP, Tipple MA, Schon- berger LB: Swine influenza virus infections: transmission from ill pigs to humans at a Wisconsin agricultural fair and subsequent probable person-to-person transmission. JAMA 1991;265:478-481.

4 Myers KP, Olsen CW, Gray GC: Cases of swine influenza in humans: a review of the literature. Clin Infect Dis 2007;44:10841088

5 Newman AP, Reisdorf E, Beinemann J, Uyeki TM, Balish A, Shu B, Lindstrom S, Achen- bach J, Smith C, Davis JP: Human case of swine influenza A (H1N1) triples reassortant virus infection, Wisconsin. Emerg Infect Dis 2008; 14:1470-1472.

6 Dawood FS, Jain S, Finelli L, Shaw MW, Lindstrom S, Garten RJ, Gubareva LV, Xu X, Bridges CB, Uyeki TM, Novel Swine-Origin Influenza A (H1N1) Virus Investigation Team: Emergence of a novel swine-origin influenza A (H1N1) virus in humans. N Engl J Med 2009;360:2605-2615. 
7 WHO: DG statement following the meeting of the Emergency Committee. http://www. who.int/csr/disease/swineflu/4th_meeting_ ihr/en/print.html.

8 Larcombe PJ, Moloney SE, Schmidt PA: Pandemic (H1N1) 2009: a clinical spectrum in the general paediatric population. Arch Dis Child 2011;96:96-98.

-9 O'Riordan S, Barton M, Yau Y, Read SE, Allen U, Tran D: Risk factors and outcomes among children admitted to hospital with pandemic H1N1 influenza. CMAJ 2010;182: 39-44.

10 Hackett S, Hill L, Patel J, Ratnaraja N, Ifeyinwa A, Farooqi M, Nusgen U, Debenham P, Gandhi D, Makwana N, et al: Clinical characteristics of paediatric H1N1 admissions in Birmingham, UK. Lancet 2009;374: 605.

11 Koliou M, Soteriades ES, Toumasi MM, Demosthenous A, Hadjidemetriou A: Epidemiological and clinical characteristics of influenza $\mathrm{A}(\mathrm{H} 1 \mathrm{~N} 1) \mathrm{v}$ infection in children: the first 45 cases in Cyprus, June to August 2009. Euro Surveill 2009;14:19312.

12 Centers for Disease Control and Prevention: Neurologic complications associated with novel influenza $\mathrm{A}(\mathrm{H} 1 \mathrm{~N} 1)$ virus infection in children - Dallas, Texas, May 2009. MMWR Morb Mortal Wkly Rep 2009;58:773-778.

13 Al-Baghli F, Al-Ateeqi W: Encephalitis-associated pandemic A (H1N1) 2009 in a Kuwaiti girl. Med Princ Pract 2011;20:191-195.
14 Coffin SE, Zaoutis TE, Rosenquist AB, Heydon K, Herrera G, Bridges CB, Watson B, Localio R, Hodinka RL, Keren R: Incidence, complications, and risk factors for prolonged stay in children hospitalized with community-acquired influenza. Pediatrics 2007;119: 740-748.

15 Ampofo K, Gesteland PH, Bender J, Mills M, Daly J, Samore M, Byington C, Pavia AT, Srivastava R: Epidemiology, complications, and cost of hospitalization in children with laboratory-confirmed influenza infection. Pediatrics 2006;118:2409-2417.

16 Ostovar GA, Rubin LG, Rajan S, Sood SK, Kohn N: Comparison of the clinical features of children hospitalized with pandemic 2009 A:H1N1 and seasonal influenza. Clin Pediatr (Phila) 2011;50:348-354

17 Bagdure D, Curtis DJ, Dobyns E, Glodé MP, Dominguez SR: Hospitalized children with 2009 pandemic influenza A (H1N1): comparison to seasonal influenza and risk factors for admission to the ICU. PLoS One 2010;5:e15173.

18 Izurieta HS, Thompson WW, Kramarz P, Shay DK, Davis RL, DeStefano F, Black S, Shinefield $\mathrm{H}$, Fukuda K: Influenza and the rates of hospitalization for respiratory disease among infants and young children. $\mathrm{N}$ Engl J Med 2000;342:232-239.
9 Saha A, Jha N, Dubey NK, Gupta VK, Kalaivani M: Swine-origin influenza A (H1N1) in Indian children. Ann Trop Paediatr 2010; 30:51-55.

20 Perez-Padilla R, de la Rosa-Zamboni D, Ponce de Leon S, Hernandez M, QuiñonesFalconi F, Bautista E, Ramirez-Venegas A, Rojas-Serrano J, Ormsby CE, Corrales A, et al: Pneumonia and respiratory failure from swine-origin influenza A (H1N1) in Mexico. N Engl J Med 2009;361:680-689.

21 Centers for Disease Control and Prevention (CDC): Hospitalized patients with novel influenza A (H1N1) virus infection - California, April-May 2009. MMWR Morb Mortal Wkly Rep 2009;58:536-541.

22 Plessa E, Diakakis P, Gardelis J, Thirios A, Koletsi P, Falagas ME: Clinical features, risk factors, and complications among pediatric patients with pandemic influenza A (H1N1). Clin Pediatr 2010;49:777-781.

23 Kumar S, Havens PL, Chusid MJ, Willoughby RE Jr, Simpson P, Henrickson KJ: Clinical and epidemiologic characteristics of children hospitalized with 2009 pandemic H1N1 influenza A infection. Pediatr Infect Dis J 2010;29:591-594.

24 Centers for Disease Control and Prevention: Intensive-care patients with severe novel influenza A (H1N1) virus infection - Michigan, June 2009. MMWR Morb Mortal Wkly Rep 2009;58:749-752. 